\title{
Treatment of Condylar Hypoplasia and Occlusal Cant Using Simultaneous Maxillomandibular Distraction Osteogenesis: A Report of 2 Cases
}

\author{
Bhagavandas Rai, Bipin A Bulgannawar*, Manju A Nair, Hiren K Vanza and Himanshu Gupta
}

Department of Oral and Maxillofacial Surgery, Pacific Dental College \& Hospital, Udaipur, Rajasthan, India

\begin{abstract}
Distraction osteogenesis is a very useful technique for various facial asymmetries. It is commonly used to lengthen the hypoplastic maxilla and mandible. Condylar hypoplasia plays a major role in creating facial asymmetry in a growing child. In such case there will be facial asymmetry with chin deviation and occlusal cant. We report two cases of acquired unilateral condylar hypoplasia and its treatment with simultaneous distraction osteogenesis of maxilla and mandible to correct facial asymmetry and occlusal cant.
\end{abstract}

Keywords: Condylar hypoplasia; Maxillomandibular distraction osteogenesis; Facial asymmetry; Occlusal cant

\section{Introduction}

Unilateral condylar hypoplasia can be either genetic (or congenital) or acquired. In the genetic group, the early differentiation of tissues and or developmental processes are affected, congenital hemifacial microsomia, micrognathia, Treacher Collins syndrome, Pierre Robin syndrome, Crouzon syndrome and cleft lip and palate exemplify the genetic group [1,2].

In the second group i.e., acquired condylar hypoplasia, the etiology is either due to local factors like trauma, mandibular infection, spread of infection from middle ear disease and radiation or due to systemic factors like infection, dietary and endocrine causes [1,2]. Acquired condylar hypoplasia may develop after the loss of one or both condylar growth centers in very early stages of life and is sometimes accompanied by ankylosis. When an affected side fails to grow downward and forward, a three dimensional asymmetry is produced. The mandibular skeletal midline deviates to the affected side, a lack of vertical growth on the same side produces a cant of the occlusal plane and mandibular retrognathia is seen as a result of the hypoplasia. The severity of the deformity depends on the degree of hypoplasia or agenesis of the tissue involved, and the more severe the deformity the greater is the probability that it will worsen with growth [1].

We are presenting two cases of condylar hypoplasia with mandibular deficiency and its treatment for canted occlusal plane and mandibular deviation.

\section{Case Reports}

Two adult patients came to the Department of Oral and Maxillofacial Surgery with complaint of facial asymmetry. Both patients had a history of fall and the mothers did not have any significant medical history during pregnancy. In both the cases chin was deviated towards right side and retruded. There was deviation of chin towards right side during mouth opening. Intraoral occlusion was class I molar relationship and there was an occlusal cant on the right side. The condylar function was normal in both the patients and no history of ankylosis (Figures 1 and 2).

Radiographic findings showed deficient condyle and shortened ramal height with prominent anti-gonial notch on right side (Figure 3).

There was hypoplastic condyle with short ramus on right side resulting in mandibular deviation towards right side and occlusal cant. The treatment plan included distraction osteogenesis of the right ramus to correct the shortened ramus along with LeFort I osteotomy to correct the occlusal cant. The direction of distraction was vertical along the long axis of ramus to increase the ramus height (Figure 4). Both the patients did not undergo presurgical orthodontics as there occlusion was angles class I.

Upper and lower arch bar wiring was done under local anaesthesia, so that during activation of distraction, maxilla can be rotated after doing inter maxillary fixation to correct occlusal cant. Unidirectional distraction was placed in right ramus region after horizontal ramus osteotomy (Figure 5). A LeFort I osteotomy performed at the level of nasal floor and the nasal septum is detached. The pterygomaxillary disjunction carried on the affected side only. The maxilla remains fixed to the pterygomaxillary suture on the unaffected side, which will serve as the pivot point for the midface rotation. Row's forceps may be used softly to assess the completeness of the osteotomy, but no attempt is made to mobilize the midface [3]. After a latency period of 5 days, inter maxillary fixation was done and activation of $1 \mathrm{~mm}$ of distraction

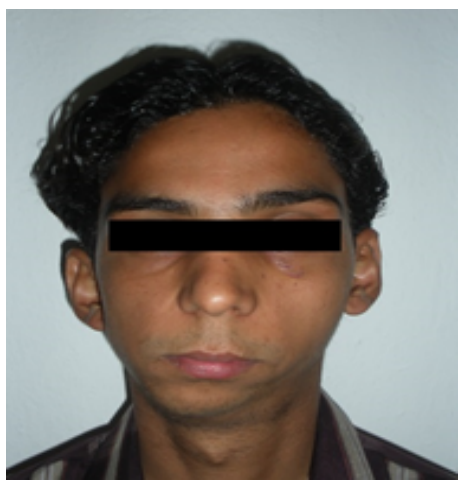

Figure 1: Preoperative front profile.

*Corresponding author: Dr. Bipin A Bulgannawar, MDS, Professor, Department of Oral and Maxillofacial Surgery, Pacific Dental College \& Hospital, Airport road, Debari, Udaipur, Rajasthan, India, Tel: +91 9663556169; E-mail: drbipinab@gmail.com

Received October 22, 2015; Accepted December 01, 2015; Published December 08, 2015

Citation: Rai B, A Bulgannawar B, Nair MA, Vanza HK, Gupta H (2015) Treatment of Condylar Hypoplasia and Occlusal Cant Using Simultaneous Maxillomandibular Distraction Osteogenesis: A Report of 2 Cases. Dentistry 5: 345. doi:10.4172/21611122.1000345

Copyright: (c) 2015 Rai B, et al. This is an open-access article distributed under the terms of the Creative Commons Attribution License, which permits unrestricted use, distribution, and reproduction in any medium, provided the original author and source are credited. 


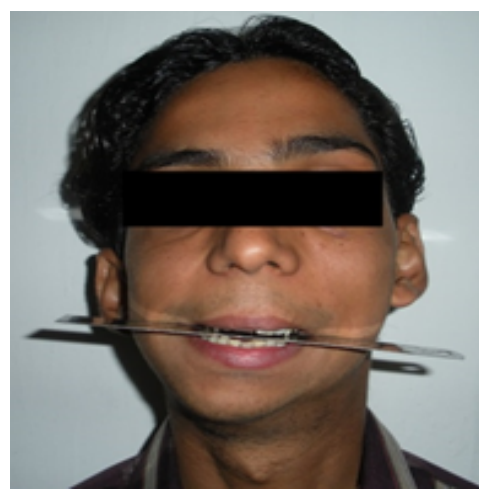

Figure 2: Pre-operative occlusal cant.

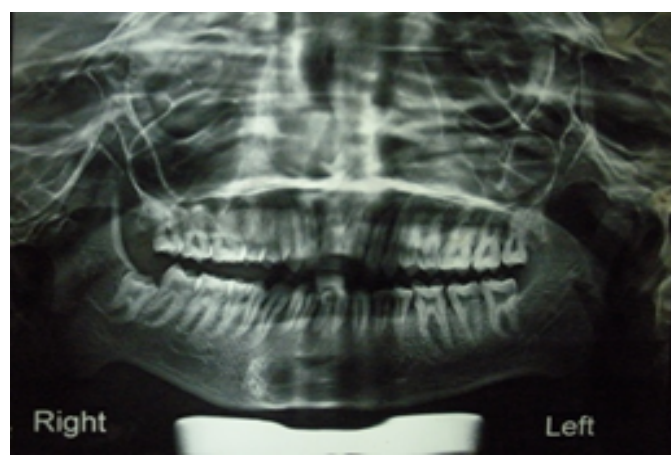

Figure 3: Pre-operative OPG showing right hypoplastic condyle.

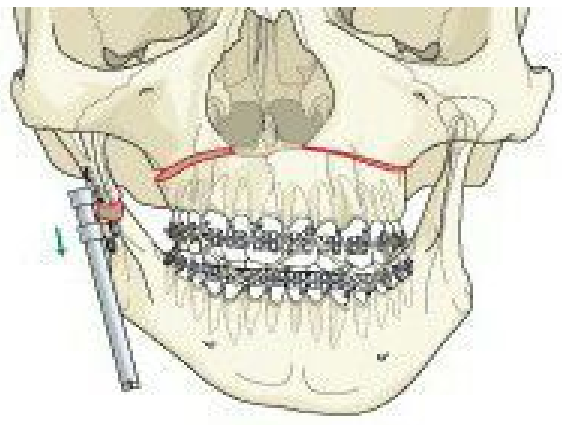

Figure 4: Diagramatic representation.

was done daily ( $0.5 \mathrm{~mm}$ in morning and $0.5 \mathrm{~mm}$ in evening). In both the patients a desired lengthening of the ramus by $13 \mathrm{~mm}$ and $14 \mathrm{~mm}$ was obtained. Patients were kept under inter maxillary fixation for 2 weeks during the activation period and an additional 2 weeks of inter maxillary fixation was kept during consolidation period. Both the patients were on five days of intravenous antibiotics. During the period of inter maxillary fixation patients were on nutritional liquid diet. Before releasing the inter maxillary fixation, plating of the maxillary osteotomy site on right side was done at the buttress region using $2 \mathrm{~mm}$ L shaped miniplate (Figure 6).

After consolidation period of 3 months, distraction was removed and horizontal advancement and centring genioplasty was done under general anaesthesia. A periodic follow up of 3, 6, 12 and 18 months showed normal midline achieved improved facial profile and corrected occlusal plane without the cant (Figures 7 and 8 ). Similar procedure and follow up was carried out in both the patients.

\section{Discussion}

The treatment options available in the literature for the management of condylar hypoplasia depend on the age. In growing patients, orthopaedic treatment with functional appliances is often helpful in correcting deformities or in reducing the worsening of the deformities with growth. If the facial asymmetry develops progressively during orthopaedic treatment, mandibular distraction osteogenesis or surgical reconstruction of the temporomandibular joint with a costochondral graft of the remaining ramus tissue may be considered. After the patient growth spurt is completed skeletal deformities can be corrected only by double jaw surgery and or genioplasty or unilateral mandibular augmentation [1].

Ferri et al., have performed a Caldwell and Letterman's vertical ramus osteotomy and distracted the ramus to the desired length. The advantage of this procedure is to treat the origin of the deformity by lengthening the ramus. The 'reinforcement' of the condylar unit with the costochondral graft preserves the functionality of the articulation, reinforces the condylar unit, allows an articular stability, and anticipates any further potential resorption of the condyle. The molar open bite is closed by an extrusion of the dentoalveolar structure in the maxilla [4].

Rubio-Bueno et al., performed horizontal ascending ramus osteotomy and distracted the ramus to the desired length. After distraction homolateral posterior and lateral open bite occurred in all patients. This open bite was temporary because of the considerable growth of the maxilla in young patients. They recommend use of intra-

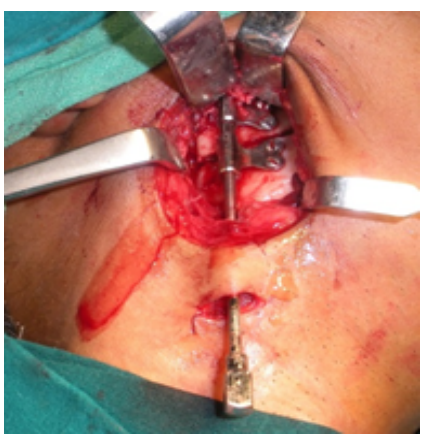

Figure 5: Placement of distractor after ramus osteotomy.

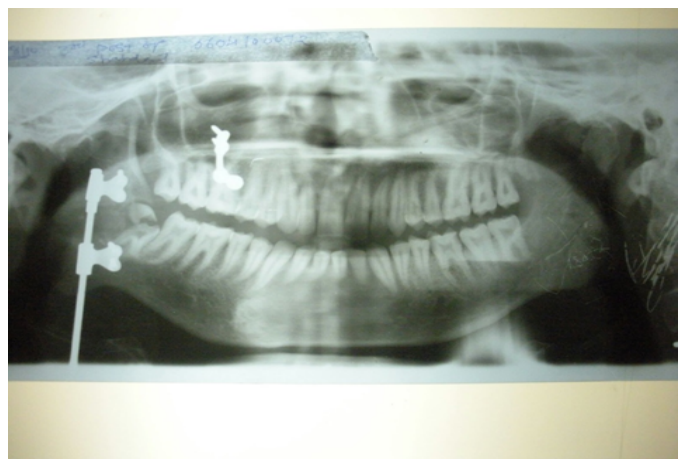

Figure 6: Post-operative OPG. 


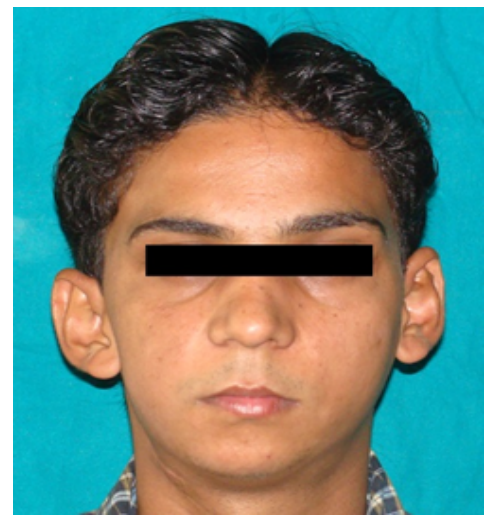

Figure 7: Post-operative front profile shows corrected facial asymmetry.

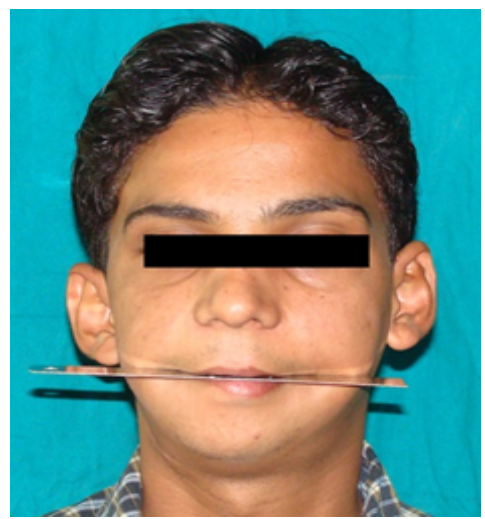

Figure 8: Post-operative corrected occlusal plane.

oral and extra-oral distractors in treating different types of mandibular hypoplasia. Intra-oral distractors are their choice for distraction of the ascending ramus of mandible in deficiency up to $25 \mathrm{~mm}$, and probably up to $40 \mathrm{~mm}$ [5]. Another technique was mentioned in the literature for the management of hemifacial microsomia which eliminates the need for bone grafts in either the maxilla or the mandible. In adult patients, they performed mandibular distraction along with standard bilateral LeFort I maxillary osteotomy, except that they left the pterygoid plates on the uninvolved side intact or the nasal septum and the nasal crest of the maxilla on the unaffected side which served as a fulcrum of the movement. After a latency period of 5 days, they established the preoperative occlusion with intermaxillary fixation (IMF) and began mandibular distraction at $1 \mathrm{~mm}$ per day. After desired maxillomandibular distraction, they achieved facial symmetry and horizontal occlusal plane $[3,6]$. The major disadvantage mentioned is the prolonged period of IMF and discomfort to the patient [6].
The primary surgical objective in the management of mandibular hypoplasia is to establish functional and aesthetic facial anatomy that remains stable long term [7]. Bone regeneration by distraction has become an accepted method of treatment of congenital and acquired mandibular hypoplasia. With this technique, significant skeletal and soft tissue enlargement in the hypoplastic area can be obtained in a short period without the need for bone grafting [5]. Distraction osteogenesis was originally described. Ilizarov used the technique to reconstruct long bones with defects without using bone or soft tissue grafts [6].

Distraction osteogenesis has been indicated in congenital micrognathia to lengthen the mandible in growing children, to widen the mandible in a child with hypoglossia-hypodactyly syndrome, also used to advance and lengthen the maxilla and midface [6]. The main advantages of distraction osteogenesis are progressive distension of all the soft tissue, resulting in facial symmetry [3] and large skeletal movements are possible without bone grafting [7].

\section{Conclusion}

We have mentioned two cases of condylar hypoplasia with occlusal cant which was treated by lengthening the ramus and levelling the occlusal plane with bimaxillary distraction osteogenesis simultaneously. We opted for this procedure because our patients were adults and had completed the growth spurts period. The total period of IMF kept was four weeks. Plating at the affected side buttress region was carried out under local anaesthesia and then inter maxillary fixation was released. This eliminated the need of keeping the patients under IMF for a prolonged period of time. This treatment gives better long term stability and soft tissue lengthening with reduced period of inter maxillary fixation and less discomfort to the patient, better nutritional support with minimal complications.

\section{References}

1. Arun T, Kayhan F, Kiziltan M (2002) Treatment of condylar hypoplasia with distraction osteogenesis: a case report. Angle Orthod 72: 371-376.

2. Ferguson MW, Whitlock RI (1978) An unusual case of acquired unilatera condylar hypoplasia. Br J Oral Surg 16: 156-162.

3. Ortiz Monasterio F, Molina F, Andrade L, Rodriguez C, Sainz Arregui J (1997) Simultaneous mandibular and maxillary distraction in hemifacial microsomia in adults: avoiding occlusal disasters. Plast Reconstr Surg 100: 852-861.

4. Ferri J, Carneiro JM, Lemiere E, Vereecke F, Baralle MM (2006) Severe congenital hypoplasia of mandibular condyle-diagnosis and treatment: a report of 2 cases. J Oral Maxillofac Surg 64: 972-980.

5. Rubio-Bueno P, Padron A, Villa E, Diaz-Gonzalez FJ (2000) Distraction osteogenesis of the ascending ramus for mandibular hypoplasia using extraoral or intraoral device: a report of 8 cases. J Oral Maxillofacial Surg 58: 593-599.

6. Padwa BL, Kearns GJ, Todd R, Troulis M, Muliken J, et al. (1999) Simultaneous maxillary and mandibular distraction osteogenesis with a semiburied device. Int J Oral Maxillfac Surg 28: 2-8.

7. Chin M (2000) Distraction osteogenesis of the ascending ramus for mandibular hyopasia using extraoral or intraoral devices: a report of 8 cases. J Oral Maxillofacial Surg 58: 600-601. 